\title{
Effect of Glomus mosseae Inoculation on the Growth of Dalbergia sissoo Seedlings with Normal, Stress and Re-watering Conditions
}

\author{
Amit Kumar $^{1}$, R. S. Beniwal ${ }^{1 *}$, M. K. Singh ${ }^{1}$, Sandeep Arya ${ }^{1}$ and Rakesh Kumar Chugh ${ }^{2}$ \\ ${ }^{1}$ Department of Forestry, ${ }^{2}$ Department of Plant Pathology, CCS Haryana Agricultural \\ University, Hisar, India \\ *Corresponding author
}

\section{A B S T R A C T}

Keywords

Dalbergia sissoo, Glomus mosseae, Normal, Drought and re-watering

Article Info

Accepted:

15 May 2020

Available Online:

10 June 2020
Pots experiment was conducted in screen house condition of Forestry Department, CCSHAU, Hisar. In this experiment Dalbergia sissoo seeds were sown in both the conditions of soils i.e. inoculated and un-inoculated with Glomus mosseae in different water treatments i.e., normal, drought and re-watering conditions to evaluate the performance of growth characters (collar diameter, shoot and root length, fresh and dry weight, no. of leaves and leaf area index) of seedlings. It was observed that seedlings which were grown in the pots containing AM fungi performed significantly better in terms of growth parameters than the seedlings which were grown in the pots with un-inoculated soils in all water treatments under studied.

\section{Introduction}

Dalbergia sissoo Roxb. commonly known as Shisham belong to the family Fabaceae, is a multipurpose tree species grown well in India, Nepal and Pakistan. It grows gregariously in alluvial soil and on freshly exposed soils along with roads, streams and for rehabilitation of degraded lands. Forest plantation sites in India are usually located on poor soils in terms of water holding capacity, fertility or drainage and also many locations of our tropical region experience frequent drought of varying intensity and duration due to erratic or scarce amount of rainfall; thus maintaining sustainable forest productivity is a major problem of prime concern. Drought is one of the most important abiotic stress factors limiting plant growth and productivity (Polle and Rennenberg, 2006). During water stress, soil water is more strongly retained and solute transfer to plants is less efficient and may not meet nutrient demands of the plants. Arbuscular mycorrhizal fungi are obligate biotrophs that forms symbiotic or mutualistic association with roots of 80 percent plants species (Cekic et al., 2012). The interaction between mycorrhizal fungi and host plants 
under different conditions has received greater attention because of their mutual association (Miransari, 2009) especially when they are subjected to stresses. Without their fungal symbionts, most trees cannot acquire enough soil resources to grow or reproduce; however, it is also true that without the trees, the fungi have insufficient energy to carry out their life cycle. Because of this obligatory exchange, mycorrhizal fungi are considered the primary vectors for plant carbon to soils (Talbot et al., 2008) and, conversely, theprimary vectors of soil nutrients to plants (Hobbie and Hobbie, 2006). Application of mineral solubilizers to the seedlings helps in the early establishment of the seedlings in problematic soils (Gupta et al., 2007). The process of inoculating microbes to the soil in a forest nursery could be an effective method to achieve higher growth (Beniwal and Toky, 1993) and establishment of tree species on water deficient sites. Mycorrhizal association at the nursery stage has been reported to enhance the productivity of forest trees like Populus x Canescens (Beniwal et al., 2010). Inoculation of plant roots with mycorrhizal fungi may be effective in improving growth under water stress conditions.

\section{Materials and Methods}

To conduct the experiment Dalbergia sissoo seedlings were maintained in the screen house of Department of Forestry, CCSHAU, Hisar situated at $29^{\circ} 10^{\prime} \mathrm{N}$ latitude and $75^{\circ} 46^{\prime} \mathrm{E}$ longitude at an elevation of $215.2 \mathrm{~m}$ above mean sea level.

The soil was taken from Balsamand Research Farm, CCSHAU, Hisar and mixed well of well rotted farm yard manure. Soil mixture was autoclaved at $121.4^{0} \mathrm{C}$ for 1 hour for two consequent days. In non-AM inoculated treatments, Dalbergia sissoo seeds were sown in pots containing of untreated sterilized soil, whereas, in AM-inoculated treatments, seeds were sown in pots containing of untreated sterilized soil with mixing of $50 \mathrm{~g} / \mathrm{kg}$ of sterilized soil of Glomus mosseae inoculums in upper $7-10 \mathrm{~cm}$ pot soil.

Uniform seeds of Dalbergia sissoo were collected from plus tree and six seeds were sown in pots; however, after germination three seedlings were maintained in each pot. Each pot received normal watering upto 90 days of growth. For the whole cycle of water stress period, normal watering (NW) plant were supplied with tap water on alternate days in the morning and rest of the seedlings were maintained without water application to observe the water stress effects on Shisham seedlings. Seedlings were subjected to drought for 25 days by withholding the water till the drooping of leaves and the plants which were maintained to determine the after effects of drought were harvested. Growth parameters under studied were recorded after each stage of water stress.

\section{Results and Discussion}

Water stress caused decreases in collar diameter, shoot and root length compared to well water plants (Table 1). These decreases were, however, less in AM-inoculated plants. A significant increment in radial growth was observed among the AM-inoculated plants compared to non-inoculated plants and it was found that the collar diameter of AM fungal inoculated plants were significantly higher than those of their respective non-inoculated counterparts at three stages of watering conditions i.e. Normal watering (NW), Drought (D), Re-watering (RW). Similarly, shoot and root lengths of AM-inoculated plants were also significantly higher than nonAM plants. Water deficit has profound effects on plant growth, even plants with an optimum water supply experience transient watershortage periods, where water absorption cannot compensate for water loss by 
transpiration. Arbuscular mycorrhizal symbiosis has been shown to increase plant tolerance to water deficit, although the exact mechanisms involved are still a matter of debate (Ruiz-lozano, 2003). The effects of Glomus mosseae on plant water status have been associated with enhanced host nutrition, especially phosphorus (P) nutrition (Almagrabi and Abdelmoneim, 2012).

In this experiment, Dalbergia sissoo seedlings were subjected to water stress for 25 days by withholding the water till the drooping of leaves. AM fungi inoculated seedlings had significantly more increased in whole plant fresh and dry weights as compared to the nonAM plants during the period of water stress (Table 2). Mean fresh weight and dry weight of plant were recorded significantly higher in AM-plants as compared with non-AM plants under normal watering, water stress and rewatering conditions. Stressed AM-inoculated seedlings could maintain a significantly higher dry weight than non AM-plants may be due to extra radical fungus mycelia, which extend the root surface area and improved the uptake of water and nutrients by the roots (Dickie, 2000). Singh and Chugh, (2019) found that seedlings of plants i.e., P.cineraira, D. sissoo, E. tereticornis, A. indica and A. excelsa grown in pots inoculated with mycorrhizae fungi performed significantly better that uninoculated soils. Further, Kaushik et al., (2003) reported that VAM inoculation increased $\mathrm{N}, \mathrm{P}$ and $\mathrm{K}$ concentration in roots and shoot in A. nilotica and D. sissoo.

Water stress also led to significant decrease in number of leaves and specific leaf area under both AM-inoculated and non-inoculated plants (Table 3). This loss was mainly caused to the seedlings as a result of wilting and leaf shedding, but wilting and leaf shedding was comparatively more in control stressed plants. Number of leaves and leaf area was found higher, in AM-plants compared to their nonAM counterparts. During recovery from water stress, all the stressed re-watered seedlings recovered well their drooped leaves; however, the non-AM plants could not recovered their drooped leaves and remained wilted till the harvest of the seedlings. Water stress caused a significant reduction in the AM abundance in the roots because of shrinking and loss of the hyphal mantle compared to well-irrigated plants. Reduction in mycorrhizal colonization owing to water stress conditions (Beniwal et al., 2010) in poplar. Kaushik et al., (2000) found that Glomus mosseae inoculation on root pathogens in Acacia nilotica and Dalbergia sissoo seedlings decreased the disease intensity and increased the $\mathrm{N}, \mathrm{P}, \mathrm{K}$ content in roots and shoots. The mycorrhizal percentage of re-watered plants was similar to that of well-watered individuals. Drought had promoted leaf shedding in Dalbergia sissoo, in all the stressed conditions of mycorrhizal and non-mycorrhizal seedlings. But leaf shedding was comparatively more in non-AM water stressed seedlings. Increased leaf shedding in moderately and severely stressed poplar in response to drought acclimation (Beniwal et al., 2010).

The periodic increment in collar diameter and shoot length from initiation of drought to drought harvest stage (25 days) and drought harvest stage to re-watering harvest stage (7 days) was also determined. In the present study, inoculation of shisham seedlings with AM-fungi resulted in the significantly more periodic increment in root collar diameter and shoot length (Table 4).It has been shown that mycorrhizal plants absorb water more efficiently under water deficit environment (Khalvati et al., 2005) that might be due to modification in root architecture which results in better root growth due to numerous branched roots (Berta et al., 2005). The findings of this work showed that the symbiotic effectiveness of Glomus mosseae 
enhanced plant total fresh and dry weight, number of leaves and leaf area in plants of Dalbergia sissoo subjected to water stress and re-watering conditions, which may be because mycorrhizal colonization caused a proportionally greater allocation of carbohydrates to the shoots and root tissues, indicating that AM-plants protected themselves against drought successfully than non AM-plants. Similar benefits of mycorrhization (Jesus et al., 2004) in Rosmarinus officinalisalso observed.

Table.1 Effect of water stress on the collar diameter, shoot and root length of AM-inoculated Dalbergia sissoo seedlings maintained at three watering regimes

\begin{tabular}{|c|c|c|c|c|c|c|c|c|c|c|c|c|c|}
\hline \multirow[t]{2}{*}{ Treatment } & & \multicolumn{3}{|c|}{$\begin{array}{c}\text { Collar diameter } \\
(\mathbf{m m})\end{array}$} & \multirow[b]{2}{*}{ Mean } & \multicolumn{3}{|c|}{$\begin{array}{l}\text { Shoot length } \\
(\mathrm{cm})\end{array}$} & \multirow[b]{2}{*}{ Mean } & \multicolumn{3}{|c|}{ Root length (cm) } & \multirow[b]{2}{*}{ Mean } \\
\hline & & NW & D & RW & & NW & D & RW & & NW & D & RW & \\
\hline Inoculated & & 4.81 & 4.25 & 4.36 & 4.47 & 51.16 & 43.47 & 46.13 & 46.92 & 28.62 & 24.28 & 25.95 & 26.28 \\
\hline \multirow[t]{2}{*}{$\begin{array}{l}\text { Non- } \\
\text { Inoculated }\end{array}$} & & 4.23 & 3.53 & 3.60 & 3.78 & 40.62 & 28.64 & 30.28 & 33.18 & 22.83 & 17.77 & 19.12 & 19.90 \\
\hline & Mean & 4.52 & 3.89 & 3.98 & & 45.89 & 36.05 & 38.81 & & 25.72 & 21.02 & 22.53 & \\
\hline CD at $5 \%$ & $\begin{array}{c}\mathrm{T} \\
\mathrm{W} \\
\mathrm{T} \times \mathrm{W}\end{array}$ & & $\begin{array}{c}0.145 \\
0.177 \\
\text { NS }\end{array}$ & & & & $\begin{array}{l}1.35 \\
1.65 \\
2.34\end{array}$ & & & & $\begin{array}{l}0.92 \\
1.13 \\
\text { NS }\end{array}$ & & \\
\hline
\end{tabular}

Values presented are means. Treatments: $\mathrm{NW}=$ Normal watering, $\mathrm{D}=\mathrm{Drought}, \mathrm{RW}=\mathrm{Re}$-watering, $\mathrm{T}=$ Treatment of soil, W= Watering conditions, NS= Non significant.

Table.2 Effect of water stress on the whole plant fresh and dry weight of AM-inoculated Dalbergia sissoo seedlings maintained at three watering regimes

\begin{tabular}{|c|c|c|c|c|c|c|c|c|c|}
\hline \multirow[b]{2}{*}{ Treatment } & & \multicolumn{3}{|c|}{ Fresh weight of plant (g) } & \multirow[b]{2}{*}{ Mean } & \multicolumn{3}{|c|}{ Dry weight of plant (g) } & \multirow[b]{2}{*}{ Mean } \\
\hline & & NW & D & RW & & NW & D & $\mathbf{R W}$ & \\
\hline Inoculated & & 17.25 & 12.12 & 13.85 & 14.40 & 11.18 & 7.99 & 9.11 & 9.42 \\
\hline \multirow{2}{*}{$\begin{array}{c}\text { Non- } \\
\text { Inoculated }\end{array}$} & & 12.79 & 6.59 & 8.12 & 9.56 & 7.68 & 4.19 & 6.11 & 5.60 \\
\hline & Mean & 15.02 & 9.35 & 10.98 & & 9.43 & 6.09 & 7.02 & \\
\hline CD at $5 \%$ & $\begin{array}{c}\mathbf{T} \\
\mathbf{W} \\
\mathbf{T} \times \mathbf{W}\end{array}$ & & $\begin{array}{l}0.41 \\
0.05 \\
0.71\end{array}$ & & & & $\begin{array}{l}0.246 \\
0.468 \\
0.945\end{array}$ & & \\
\hline
\end{tabular}

Values presented are means. Treatments: $\mathrm{NW}=$ Normal watering, $\mathrm{D}=$ Drought, $\mathrm{RW}=\mathrm{Re}$-watering, $\mathrm{T}=$ Treatment of soil, $\mathrm{W}=$ Watering conditions.

Table.3 Effect of water stress on the number of leaves and leaf area of AM-inoculated Dalbergia sissoo seedlings maintained at three watering regimes

\begin{tabular}{|c|c|c|c|c|c|c|c|c|c|}
\hline \multirow[b]{2}{*}{ Treatment } & & \multicolumn{3}{|c|}{ No. of leaves } & \multirow[b]{2}{*}{ Mean } & \multicolumn{3}{|c|}{ Leaf area $\left(\mathrm{cm}^{2}\right)$} & \multirow[b]{2}{*}{ Mean } \\
\hline & & NW & D & RW & & NW & D & $\mathbf{R W}$ & \\
\hline Inoculated & & 48.20 & 30.21 & 32.05 & 36.81 & 35.69 & 25.44 & 26.19 & 29.10 \\
\hline Non- Inoculated & & 36.67 & 15.73 & 16.57 & 22.99 & 24.54 & 19.79 & 20.60 & 22.31 \\
\hline & Mean & 42.43 & 22.97 & 24.31 & & 31.12 & 22.61 & 23.39 & \\
\hline CD at $5 \%$ & $\begin{array}{c}\mathbf{T} \\
\mathbf{W} \\
\mathbf{T} \times \mathbf{W}\end{array}$ & & $\begin{array}{l}0.47 \\
0.59 \\
0.73\end{array}$ & & & & $\begin{array}{l}0.65 \\
0.80 \\
1.13\end{array}$ & & \\
\hline
\end{tabular}

Values presented are means. Treatments: NW= Normal watering, $\mathrm{D}=\mathrm{Drought}, \mathrm{RW}=\mathrm{Re}$-watering, $\mathrm{T}=$ Treatment of soil, W= Watering conditions. 
Table.4 Effect of water stress on the periodic increment in collar diameter and shoot length of AM-inoculated Dalbergia sissoo seedlings

\begin{tabular}{|c|c|c|c|c|c|c|c|}
\hline \multirow[b]{2}{*}{ Treatment } & & \multicolumn{2}{|c|}{ Collar diameter (mm) } & \multirow[b]{2}{*}{ Mean } & \multicolumn{2}{|c|}{ Shoot length (cm) } & \multirow[b]{2}{*}{ Mean } \\
\hline & & $\begin{array}{l}\text { NW-D } \\
\text { (25 d) }\end{array}$ & $\begin{array}{c}\text { D-RW } \\
\text { (7 d) }\end{array}$ & & $\begin{array}{l}\text { RW-D } \\
\text { (25 d) }\end{array}$ & $\begin{array}{c}\text { D-RW } \\
\text { (7 d) }\end{array}$ & \\
\hline Inoculated & & 0.68 & 0.21 & 0.45 & 8.54 & 2.32 & 5.43 \\
\hline Non-Inoculated & & 0.31 & 0.14 & 0.23 & 4.34 & 1.78 & 3.06 \\
\hline & Mean & 0.50 & 0.16 & & 6.44 & 2.05 & \\
\hline CD at $5 \%$ & $\begin{array}{c}\mathrm{T} \\
\mathrm{W} \\
\mathrm{T} \times \mathrm{W}\end{array}$ & \multicolumn{2}{|c|}{$\begin{array}{c}0.012 \\
0.015 \\
\text { NS }\end{array}$} & & \multicolumn{2}{|c|}{$\begin{array}{l}0.99 \\
0.13 \\
1.12\end{array}$} & \\
\hline
\end{tabular}

Values presented are means. Treatments: $\mathrm{NW}=$ Normal watering, $\mathrm{D}=$ Drought, $\mathrm{RW}=\mathrm{Re}$-watering, $\mathrm{T}=$ Treatment of soil, $\mathrm{W}=$ Watering conditions, $\mathrm{NS}=$ Non significant, $\mathrm{d}=$ days

The AM contribution to plant drought tolerance might also have occurred through drought avoidance mechanisms such as hyphal water uptake (Marulanda et al., 2003) or increased water uptake related to mycorrhizal changes in root morphology or soil structure.

It may be concluded that AM-inoculation substantially protected plant growth performance compared with non-AM shisham. Upon microscopically looking the AM-inoculated shisham root segments, it was found that Glomus mosseae penetrates the cortical cells of feeder roots intra-cellularly and make large vesicles and arbuscules in root cells and thus, helped the shisham plants in increasing the effective absorption root surface area, which cause the flow of moisture and nutrient to plants that ultimately increase the plant growth by increasing relative water content. It is suggested that using the arbuscular mycorrhizal fungi in water stressed Dalbergia sissoo seedlings, we can achieve the increased growth in AM shisham plants and thus the adverse effect of water stress on them can be minimized.

\section{References}

Almagrabi, O.A. and Abdelmoneim, T.S. (2012). Using of Arbuscular mycorrhizal fungi to reduce the deficiency effect of phosphorous fertilization on maize plants (Zea mays L.). Life Science Journal, 9: 1648-1654. Beniwal, R.S. and Toky, O.P. (1993). Growth and nodulation of Acacia nilotica (L.) willd ex Del. as influenced by Rhizobium inoculation and nitrogen fertilizer. Crop Research, 6: 520-524.

Beniwal, R.S., Langenfeld-Heyser, R. and Polle, A. (2010). Ectomycorrhiza and hydrogel protect hybrid poplar from water deficit and unravel plastic responses of xylem anatomy. Environ Exp. Bot., 69: 189-194.

Berta, G., Sampo, S., Gamalero, E., Massa, N. and Lemanceau, P. (2005). Suppression of Rhizoctonia root-rot of tomato by Glomus mossae BEG12 and Pseudomonas fluorescens A6RI is associated with their effect on the pathogen growth and on the root morphogenesis. Eur. J. Plant Pathol., 111: 279-88.

Cekic, F.O., Unyayar, S., and Ortas, I. (2012). Effects of arbuscular mycorrhizal inoculation on biochemical parameters in Capsicum annuum grown under long term salt stress. Turk. J. Bot., 36:63-72.

Dickie, I.A. (2000). Mycorrhizal infection, nutrition and growth of Quercus rubra L. seedlings as influenced by overstory trees on a disturbed forest site. Ph.D. thesis, The Pennsylvania State 
University, USA

Gupta, N., Sabat, J., Parida, R. and Kerkatta, P. (2007). Solubilization of tricalcium phosphate and rock phosphate by microbes isolated from chromite, iron and manganese mine soils. Acta Botanica Croatica, 66: 197-204.

Hobbie, J.E. and Hobbie, E.A. (2006). $15 \mathrm{~N}$ in symbiotic fungi and plants estimates nitrogen and carbon flux rates in Arctic. Ecology, 87: 816-822.

Jesus, S M., Trinitario, F., Angeles, M., Asuncion, M. and Juan Jose, A. (2004). Variations in water status, gas exchange, and growth in Rosmarinus officinalis plants infected with Glomus deserticola under drought conditions. Journal of Plant Physiology, 161: 675682.

Khalvati, M.A., Hu, Y., Mozafar, A. and Schmidhalter, U. (2005). Quantification of water uptake by arbuscular mycorrhizal hyphae and its significance for leaf growth, water relations, and gas exchange of barley subjected to drought stress. Plant Biol,. 7: 706-12.

Kaushik, J.C.; Dabas, P. and Kumar, R. (2000).lmpact of Glomus mosseae inoculation on root pathogens in Acacia nilotica and Dalbergia sissoo seedlings. Indian J. Forestry, 23 (3): 238-240.

Kaushik, J.C.; Dabas, P. and Kumar, R. (2003). Influence of Glomus mosseae, Phosphorus and drought stress on the nodulation and nutrient content of Acacia nilotica and Dalbergia sissoo seedlings. Indian J. Forestry, 26(1): 1113.
Marulanda, A., Azcon, R. and Ruiz-Lozano, J.M. (2003). Contribution of six arbuscular mycorrhizal fungal isolates to water uptake by Lactuca sativa L. plants under drought stress. Physiologia Plantarum, 119: 526-533.

Miransari, M. (2009). Contribution of arbuscular mycorrhizal symbiosis to plant growth under different types of soil stress. Plant Biol., 12:563-569.

Polle, A. and Rennenberg, H. (2006). Physiological reponses of forest trees to heat and drought. Plant Biology , 8: 556-571.

Ruiz-Lozano, J.M.(2003). Arbuscular mycorrhizal symbiosis and alleviation of osmotic stress: new perspectives for molecular studies. Mycorrhiza, 13: 309317.

Singh, M.K and Chugh, R.K (2019). Impact of Arbuscular Mycorrhizal fungi on the growth parameters and nutrient content on different tree species. Ind. J. Pure App. Biosci., 7(6): 244-248.

Talbot, J.M., Allison, S.D. and Treseder, K.K.(2008). Decomposers in disguise: mycorrhizal fungi as regulators of soil carbon dynamics in ecosystems under global change. Functional Ecology, 22: 955-963.

Zhu, J., Li, F., Xu, M. and Wu, X. (2008). The role of ectomycorrhizal fungi in alleviating pine decline in semiarid sandy soil of northern China: an experimental approach. Annals of Forest Science, vol. 65, no. 3.

\section{How to cite this article:}

Amit Kumar, R. S. Beniwal, M. K. Singh, Sandeep Arya and Rakesh Kumar Chugh. 2020. Effect of Glomus mosseae Inoculation on the Growth of Dalbergia sissoo Seedlings with Normal, Stress and Re-watering Conditions. Int.J.Curr.Microbiol.App.Sci. 9(06): 781-786. doi: https://doi.org/10.20546/ijcmas.2020.906.100 